\title{
Factors influencing the use of biologic therapy and adoption of treat-to-target recommendations in current European rheumatology practice
}

This article was published in the following Dove Press journal:

Patient Preference and Adherence

Peter C Taylor,' Rieke Alten, ${ }^{2}$ Juan J Gomez Reino, ${ }^{3}$ Roberto Caporali, ${ }^{4}$ Philippe Bertin, ${ }^{5}$ Emma Sullivan, ${ }^{6}$ Robert Wood, ${ }^{6}$ James Piercy, ${ }^{6}$ Radu Vasilescu, ${ }^{7}$ Dean Spurden, ${ }^{8}$ Jose Alvir, ${ }^{9}$ Miriam Tarallo ${ }^{10}$

'Botnar Research Centre, Nuffield Department of Orthopaedics, Rheumatology and Musculoskeletal Sciences, University of Oxford, Oxford, UK; ${ }^{2}$ Department of Internal Medicine II, Rheumatology, Clinical Immunology, and Osteology, Schlosspark Klinik, University Medicine Berlin, Berlin, Germany; ${ }^{3}$ Experimental and Observational Rheumatology and Rheumatology Unit, Fundacion Ramon Dominguez and Rheumatology, Hospital Clinico Universitario, Santiago de Compostela, Spain; ${ }^{4}$ Division of Rheumatology, IRCCS Foundation Policlinico S. Matteo, University of Pavia, Pavia, Italy; ${ }^{5}$ Service de Rhumatologie, $\mathrm{CHU}$ Dupuytren, Limoges, France; ${ }^{6}$ Real-World Evidence and Epidemiology, Adelphi Real World, Bollington, UK; ${ }^{7}$ Medical Affairs, International Developed Markets, Pfizer, Brussels, Belgium; ${ }^{8}$ Health Economics and Outcomes Research, Pfizer Ltd, Tadworth, UK; ${ }^{9}$ Statistical Research and Data Science Center, Global Product Development, Pfizer Inc, New York, NY, USA; ${ }^{10}$ Patient and Health Impact, Pfizer Italia Srl, Rome, Italy

Correspondence: Peter C Taylor Botnar Research Centre, Nuffield Department of Orthopaedics, Rheumatology and Musculoskeletal Sciences, University of Oxford, Windmill Road, Oxford, OX3 7LD, UK

Tel +44 I865227323

Email peter.taylor@kennedy.ox.ac.uk
Objective: The aim of this study was to identify factors that influence treatment adjustments and adoption of a treat-to-target (T2T) strategy in patients with rheumatoid arthritis (RA) in European practices.

Methods: Cross-sectional data were drawn from the Adelphi 2014 RA Disease Specific Programme. Treatment patterns and clinical characteristics were investigated in patients treated with biologic disease-modifying antirheumatic drugs (bDMARDs) vs non-bDMARDs. For the T2 $\mathrm{T}$ analysis, patients were subdivided into two subsets (RA diagnosis $<2$ or $\geq 2$ years) and compared according to the approach used (no target $=$ no T2 $\mathrm{T}$ approach; pragmatic $=$ target different from remission; and aspirational = target set as remission).

Results: Data from 2,536 patients were analyzed (mean age: 52.76 years and mean time since RA diagnosis: 6.05 years). Of the 1,438 patients eligible to receive bDMARDs, 55\% did not receive them. Initiation of bDMARDs in a bDMARD-naïve patient was prompted by worsening of the disease. In the RA diagnosis $<2$ years subset, a T2T approach was not adopted in $58 \%$ of the patients, whereas $8 \%$ and $34 \%$ adopted a pragmatic and aspirational approach, respectively. In the RA diagnosis $\geq 2$ years subset, $45 \%, 19 \%$, and $36 \%$ of the patients adopted a no target, pragmatic, and aspirational approach, respectively. Physician satisfaction with RA control was lower in the RA diagnosis $<2$ years subset than in the RA diagnosis $\geq 2$ years subset $(65 \%$ vs $77 \%$ satisfied, respectively; $P<0.0001$ ).

Conclusion: This analysis shows that the use of bDMARDs remains suboptimal and that a T2T strategy is not universally adopted.

Keywords: rheumatoid arthritis, treat-to-target, disease-modifying antirheumatic drugs

\section{Introduction}

Rheumatoid arthritis (RA) is a chronic autoimmune disease characterized by inflammation and deterioration of the joints. RA causes significant loss of functionality and increases morbidity and mortality. ${ }^{1}$

Treatment for RA involves early initiation of disease-modifying antirheumatic drugs (DMARDs). ${ }^{2,3}$ Current European League Against Rheumatism (EULAR) recommendations support the use of conventional synthetic DMARDs (csDMARDs), such as methotrexate, as first-line therapy, combined with glucocorticoids for a limited time. Biologic DMARDs (bDMARDs) or targeted synthetic DMARDs (tsDMARDs) may be combined with a csDMARD if csDMARD therapy fails. ${ }^{3}$ The wide array of DMARDs available enables optimum disease management by allowing monotherapy or combination therapy, different dose titrations, and treatment switching. The recommendations suggest that treatment assessments should be made every 1-3 months 
in patients with high-to-moderate disease activity and that therapy adjustments should be made every 3-6 months if the target has not been reached. ${ }^{2}$

EULAR recommendations state that the primary target for all patients with RA should be sustained remission or low disease activity (LDA), the latter for patients with long-standing or aggressive disease. ${ }^{3}$ In addition, the American College of Rheumatology (ACR) recommends an aggressive therapy approach in patients with early RA to achieve better outcomes and prevent damage progression. ${ }^{2}$ Indeed, early RA evaluation and treatment appear to be critical in optimizing the subsequent response. ${ }^{4,5}$ Better disease control can be achieved by adopting a treat-to-target (T2T) approach, which has been shown to be beneficial in various illnesses. ${ }^{6-10}$ This strategy is based on setting therapeutic targets that are reached through frequent assessments and drug therapy adjustments in order to optimize treatment. The assessments require measurement of disease activity using validated metrics to enable informed treatment decisions. A T2T approach is widely accepted to improve outcomes in patients with RA, ${ }^{11-13}$ but has not been universally adopted. ${ }^{14}$

One of the aims of this study was to identify the factors influencing the introduction of bDMARD treatment in RA patients in a real-world setting, the choice of a specific bDMARD, and switching from one class of bDMARD to another. A further objective was to assess the adoption of a T2T strategy for the treatment of RA and physician satisfaction with different targets in the T2T management approach.

\section{Methods}

\section{Study design}

This was an analysis of cross-sectional data drawn from the Adelphi 2014 RA Disease Specific Programme (DSP), a point-in-time survey of rheumatologists and their patients with RA. The DSP aims to provide impartial observations of realworld clinical practice from a physician and matched patient viewpoint without consideration of current guidelines, but with the intention of providing a view on contemporary RA management. The survey was conducted in France, Germany, Italy, Spain, and the UK from January to August 2014. Patients provided written informed consent for use of their anonymized and aggregated data for research and publication in scientific journals. For each patient meeting the eligibility criteria, the physicians filled out a patient record form (PRF), which included questions on demographics, symptoms, past and current treatments, compliance, and general patient management. Data were collected in such a way that patients and physicians could not be identified directly; all data were aggregated and de-identified before receipt. Data collection was undertaken in line with the European Pharmaceutical Marketing Research Association (EPhMRA) guidelines and as such it did not require ethics committee approval. ${ }^{15}$ The survey was performed in full accordance with relevant legislation at the time of data collection, including the Health Insurance Portability and Accountability Act, ${ }^{16}$ a cornerstone of the EPhMRA guidelines relating to data privacy.

Local fieldwork teams identified and invited rheumatologists to participate in the study upon fulfillment of the inclusion criteria listed subsequently. Compensation was set according to time spent on the study at fair market rates. Each rheumatologist recruited the first eight consecutive patients who consulted them and satisfied the inclusion criteria.

For the analysis of bDMARD use, the clinical and disease characteristics and satisfaction level of patients with moderateto-severe RA were compared among patients who received a bDMARD vs those who did not (non-bDMARD). For the assessment of adoption of a T2T approach/strategy, as this approach is particularly recommended during the early phase of the disease, the patients were subdivided into two subsets: RA diagnosis $<2$ years and RA diagnosis $\geq 2$ years. Physicians indicated the T2T goal they adopted as either remission (defined as disease activity score in 28 joints [DAS28] $<2.6$ ), LDA (DAS28 <3.2), or other target. Patients were subsequently compared according to the T2T approach used: no target (patients treated without a $\mathrm{T} 2 \mathrm{~T}$ approach), pragmatic (T2T target set as LDA or something other than remission), or aspirational (T2T goal set as remission).

\section{Physicians and patients}

Only rheumatologists who qualified between 1975 and 2010 and who were actively involved in RA management were included in the DSP. In addition, rheumatologists were required to manage more than eight patients with RA in a calendar month. Patients with RA were eligible for inclusion if they were $\geq 18$ years of age and were not involved in clinical trials for RA. In order to be considered eligible for bDMARD therapy, patients had to have received at least one csDMARD before their current treatment, have moderate-to-severe RA at the initiation of their current treatment (as reported by the physician), and remain on that current treatment for $\geq 6$ months to determine effectiveness. In addition, these patients had to have consulted a physician who was authorized to initiate bDMARDs. Assessment of the severity of RA (mild, moderate, or severe) was based on the physician's own perception of the disease status. For the assessment of the adoption of a T2T strategy, patients with an unknown time since RA diagnosis were excluded. 


\section{Statistical analyses}

Mean and standard deviation (SD) for numerical outcomes and frequency and percentage of patients within each response for nominal outcomes were reported. Statistical differences were assessed using Mann-Whitney $U$ or Kruskal-Wallis test for numeric outcomes, and chi-squared or Fisher's exact test for nominal outcomes.

Missing data were not imputed. Any patients with missing values for a particular variable were removed for all analyses where that variable was used, but remained eligible for inclusion in other analyses.

\section{Results}

Overall, 307 rheumatologists provided data on a total of 2,536 patients from across Europe (France: $\mathrm{n}=502$; Germany: $\mathrm{n}=491$; Italy: $\mathrm{n}=501$; Spain: $\mathrm{n}=486$; and UK: $\mathrm{n}=556$ ). The mean (SD) age of the patients was 52.76 (14.32) years and the mean (SD) time since diagnosis of RA was 6.05 (6.81) years (Table 1). The majority ( $71 \%$ ) of the patients were women, and $63 \%$ of the patients had never received bDMARDs. Of the $37 \%$ of patients ( $\mathrm{n}=926)$ who had previously received a bDMARD, $93 \%$ of these were currently receiving bDMARD therapy (the remaining $7 \%$ had discontinued bDMARD therapy) and $68 \%$ had received only one prior bDMARD therapy.

For the analysis of bDMARD use, 126 patients were excluded because it could not be determined whether these patients were receiving bDMARD or non-bDMARD treatment at the time of the survey due to missing or contradictory information. Clinical characteristics of the remaining patients are shown in Table 2. The patients on bDMARD therapy had a significantly longer time since RA diagnosis compared with

Table I Overall patient demographics

\begin{tabular}{|c|c|}
\hline Characteristics & $\begin{array}{l}\text { Patients } \\
(\mathrm{N}=2,536)\end{array}$ \\
\hline Age, years, mean $(S D)^{a}$ & $52.76(14.32)$ \\
\hline Female, $\mathrm{n}(\%)$ & $\mathrm{I}, 808(7 \mathrm{I})$ \\
\hline $\mathrm{BMI}, \mathrm{kg} / \mathrm{m}^{2}$, mean (SD) ${ }^{\mathrm{b}}$ & $25.22(4.29)$ \\
\hline Time since RA diagnosis, years, mean (SD) ${ }^{c}$ & $6.05(6.8 I)$ \\
\hline \multicolumn{2}{|c|}{ Disease severity at the initiation of current treatment, $n(\%)$} \\
\hline Mild & $345(14)$ \\
\hline Moderate & $\mathrm{I}, 4 \mathrm{I} 7(56)$ \\
\hline Severe & $774(31)$ \\
\hline \multicolumn{2}{|l|}{ Prior bDMARD therapy, $\mathrm{n}(\%)$} \\
\hline Yes & $926(37)$ \\
\hline No & $1,610(63)$ \\
\hline Currently still receiving bDMARD therapy ${ }^{d}$ & $859(93)$ \\
\hline
\end{tabular}

Notes: a Data missing from eleven patients. 'Data missing from two patients. 'Data missing from 155 patients. 'Data are a subset of the 926 patients in the 'Yes' category of this variable.

Abbreviations: bDMARD, biologic disease-modifying antirheumatic drug; BMI, body mass index; RA, rheumatoid arthritis. the patients who were not on a bDMARD ( 8.62 vs 6.69 years, respectively; $P<0.0001)$. These patients also had a more severe condition at the initiation of their current treatment as perceived by rheumatologists ( $52 \%$ vs $27 \%$ with severe RA, respectively; $P<0.0001)$ and were experiencing more pain at the initiation of their current treatment (mean levels of pain on a $1-10$ scale were 7.13 vs 6.44 , respectively; $P<0.0001$; Table 2). The two main reasons why rheumatologists chose to initiate bDMARD therapy in patients receiving bDMARDs were "strong overall efficacy" of bDMARD therapy (71\%) and "convincing efficacy shown in clinical trials" (55\%; Figure 1A). When switching between bDMARD therapies occurred, the principal reasons that prompted the patient's most recent change in bDMARD treatment were "worsening of the condition" (46\%) and "loss of response over time" (38\%; Figure 1B). Second-line bDMARD therapies were chosen based on similar reasons as for the first-line bDMARDs, even when switching to a different class of bDMARD. The main reasons that would prompt initiation of a bDMARD in those patients who were still bDMARDnaive (as stated by the physician) were worsening of the disease (61\%) and failure of non-bDMARD therapy $(33 \%)$ as assessed by the physician (Figure 1C). In 7\% of the patients, physicians stated that nothing would prompt bDMARD initiation (ie, bDMARDs were likely contraindicated).

Only patients for whom the time since RA diagnosis was known were included in the assessment of T2T strategy adoption $(n=2,381)$. The baseline characteristics of these patients are shown in Table 3. Twenty-four percent of the patients $(\mathrm{n}=579)$ had been diagnosed with RA for $<2$ years and $76 \%$ $(\mathrm{n}=1,802)$ for $\geq 2$ years. A T2T approach was not adopted ("no target") in 1,144 patients (regardless of time since RA diagnosis), whereas physicians adopted a pragmatic approach in 395 patients and an aspirational approach in 842 patients. A higher proportion of patients in the RA diagnosis $<2$ years subset had no target than those in the $\geq 2$ years subset $(58 \%$ vs $45 \%$, respectively; Table 3 ), and fewer had a pragmatic one ( $8 \%$ vs $19 \%$, respectively; Table 3 ). The percentage of patients with an aspirational target was similar in both subsets $(34 \%$ vs $36 \%$, respectively; Table 3 ). In the $<2$ years subset, $7-9 \%$ of the patients were currently receiving bDMARDs across all T2T subgroups, whereas in the $\geq 2$ years subset, $38 \%, 42 \%$, and $52 \%$ of the patients received bDMARDs in the no target, pragmatic, and aspirational subgroups, respectively.

Physician satisfaction with RA control was lower in the RA diagnosis $<2$ years subset than in the RA diagnosis $\geq 2$ years subset ( $65 \%$ [377/579] vs $77 \%$ [1,387/1,802] satisfied, respectively). In the RA diagnosis $<2$ years subset, 
Table 2 Clinical characteristics of patients according to DMARD therapy group

\begin{tabular}{|c|c|c|c|c|}
\hline Characteristics & $\begin{array}{l}\text { Overall } \\
(N=2,4 \mid 0)\end{array}$ & $\begin{array}{l}\text { Currently on } \\
\text { non-bDMARD }(n=I, 55 I)\end{array}$ & $\begin{array}{l}\text { Currently on } \\
\text { bDMARD }(n=859)\end{array}$ & $P$-value \\
\hline Time since diagnosis, years, mean (SD) & $5.95(6.68)$ & $4.76(6.39)$ & $8.13(6.67)$ & $<0.000 I^{\mathrm{a}}$ \\
\hline Missing & $|4|$ & 79 & 62 & \\
\hline Disease severity at initiation of current treatment, $\mathrm{n}(\%)$ & & & & $<0.000 I^{b}$ \\
\hline Mild & $324(13)$ & $292(19)$ & $32(4)$ & \\
\hline Moderate & $\mathrm{I}, 358(56)$ & $942(61)$ & $416(48)$ & \\
\hline Severe & $728(30)$ & $317(20)$ & $411(48)$ & \\
\hline $\begin{array}{l}\text { Level of pain at initiation of current treatment } \\
(I=\text { none; } I 0=\text { worst }), \text { mean }(S D)\end{array}$ & $6.17(2.17)$ & $5.72(2.22)$ & $7.00(1.82)$ & $<0.000 \mathrm{I}^{\mathrm{a}}$ \\
\hline Characteristics of bDMARD-eligible ${ }^{c}$ patients & $\begin{array}{l}\text { Overall } \\
(n=1,438)\end{array}$ & $\begin{array}{l}\text { Currently on } \\
\text { non-bDMARD }(n=796)\end{array}$ & $\begin{array}{l}\text { Currently on } \\
\text { bDMARD }(n=642)\end{array}$ & $P$-value \\
\hline Time since diagnosis, years, mean (SD) & $7.54(7.2 \mathrm{I})$ & $6.69(7.40)$ & $8.62(6.82)$ & $<0.000 I^{a}$ \\
\hline Missing & 99 & 49 & 50 & \\
\hline Disease severity at initiation of current treatment, $\mathrm{n}(\%)$ & & & & $<0.000 I^{b}$ \\
\hline Moderate & $895(62)$ & $585(73)$ & $310(48)$ & \\
\hline Severe & $543(38)$ & $211(27)$ & $332(52)$ & \\
\hline $\begin{array}{l}\text { Level of pain at initiation of current treatment } \\
(I=\text { none; } 10=\text { worst }), \text { mean }(S D)\end{array}$ & $6.75(1.77)$ & $6.44(1.80)$ & $7.13(1.65)$ & $<0.000 \mathrm{I}^{\mathrm{a}}$ \\
\hline
\end{tabular}

physician-reported satisfaction with RA control differed significantly across T2T subgroups and was highest in the "no target" subgroup (70\% vs $64 \%$ vs $56 \%$ satisfied in no target, pragmatic, and aspirational subgroups, respectively; $P=0.0040$; Table 3). However, in the RA diagnosis $\geq 2$ years subset, while physician-reported satisfaction with RA control differed significantly across T2T subgroups, it was highest in the aspirational subgroup (79\% vs $63 \%$ vs $82 \%$ satisfied in the no target, pragmatic, and aspirational subgroups, respectively; $P<0.0001$; Table 3 ).

\section{Discussion}

These data from the Adelphi 2014 RA DSP study provide valuable insights into the factors affecting treatment adjustments in RA management in current European practices. For instance, escalation of treatment from csDMARD to bDMARD seems to be triggered by worsening of the disease rather than high baseline RA activity. Current recommendations in RA management, however, advise that physicians should aim for remission or LDA in order to prevent further damage. ${ }^{2,3}$ This study suggests that the goals of early intervention and optimal disease control are not satisfactorily achieved in these patients.

A large proportion of patients did not receive any bDMARDs even though they experienced pain and their condition was perceived as "moderate-to-severe" by physicians. The reason for this requires further investigation.
When bDMARD therapy was prescribed, first and second bDMARDs were chosen according to the perceived efficacy and safety of the bDMARD derived from clinical trial data and/or the individual physician's professional experience, which is in agreement with the results from a previous study. ${ }^{17}$

In our analysis sample, $68 \%$ of those patients who had previously received a bDMARD had only ever received one bDMARD therapy ( $n=926)$, even if 1,438 patients had moderate-to-severe RA and were considered potentially eligible for bDMARD at the initiation of current treatment. Previous studies have shown that initial treatment with TNF inhibitors can fail due to intolerance, inefficacy, or loss of efficacy, and that prior exposure to TNF inhibitors results in a decline in the proportion of patients responding to subsequent biologic treatment, including a decline of about $10 \%$ in ACR categorical response criteria for the same class of bDMARDs. ${ }^{18,19}$ Such observations may delay a physician's decision to switch to other bDMARDs. However, switching to another drug of this group may still be beneficial in some patients. ${ }^{18}$ Indeed, an immediate switch to a second bDMARD within the TNF inhibitor class after failure of the first bDMARD has previously proven to be effective in achieving better disease control in approximately $60 \%$ of the nonresponders to first bDMARD. ${ }^{20}$

In the T2T adoption analysis, a T2T approach was not adopted in almost half of the patients with RA even though 
A

Physician-reported reason (\%)

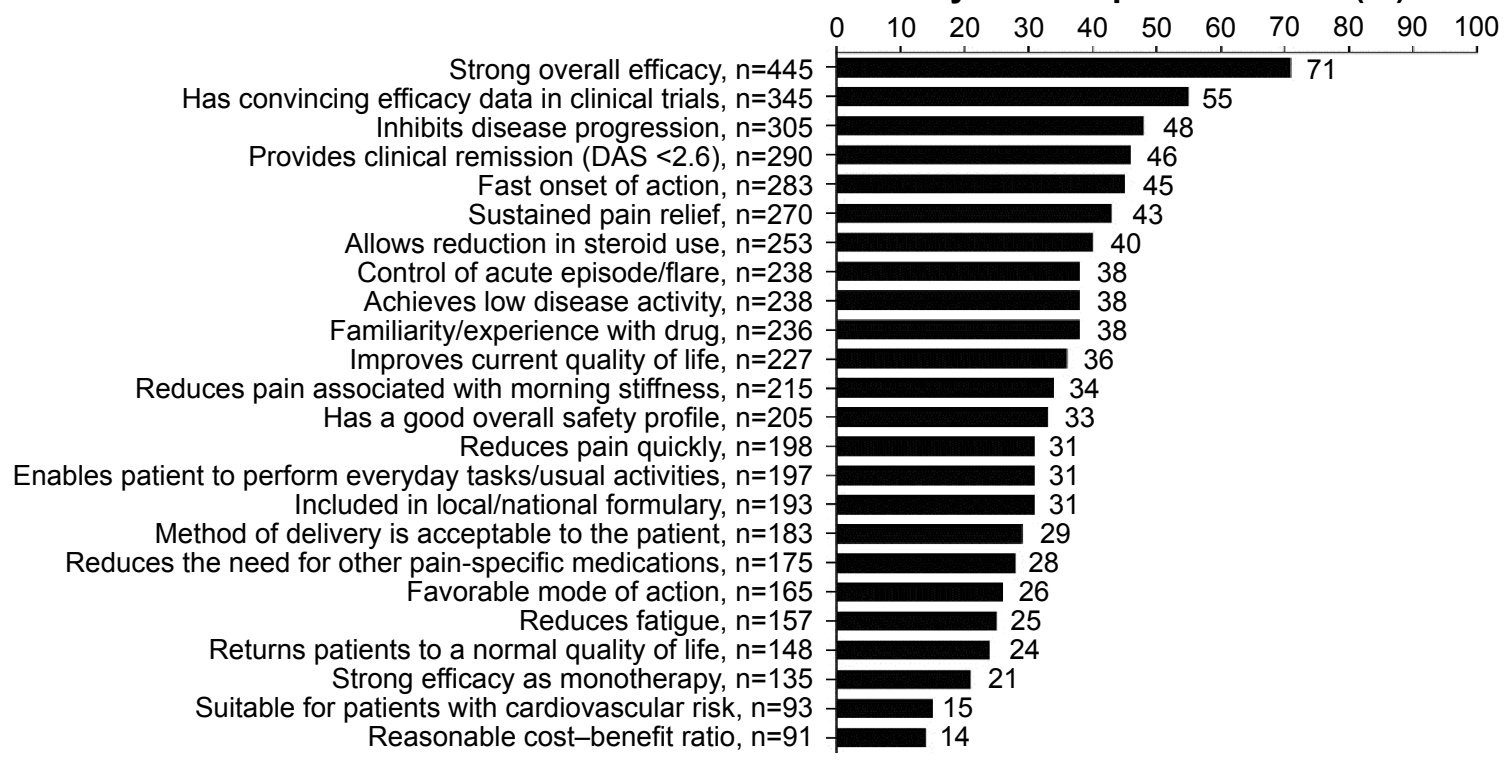

B

Physician-reported reason (\%)

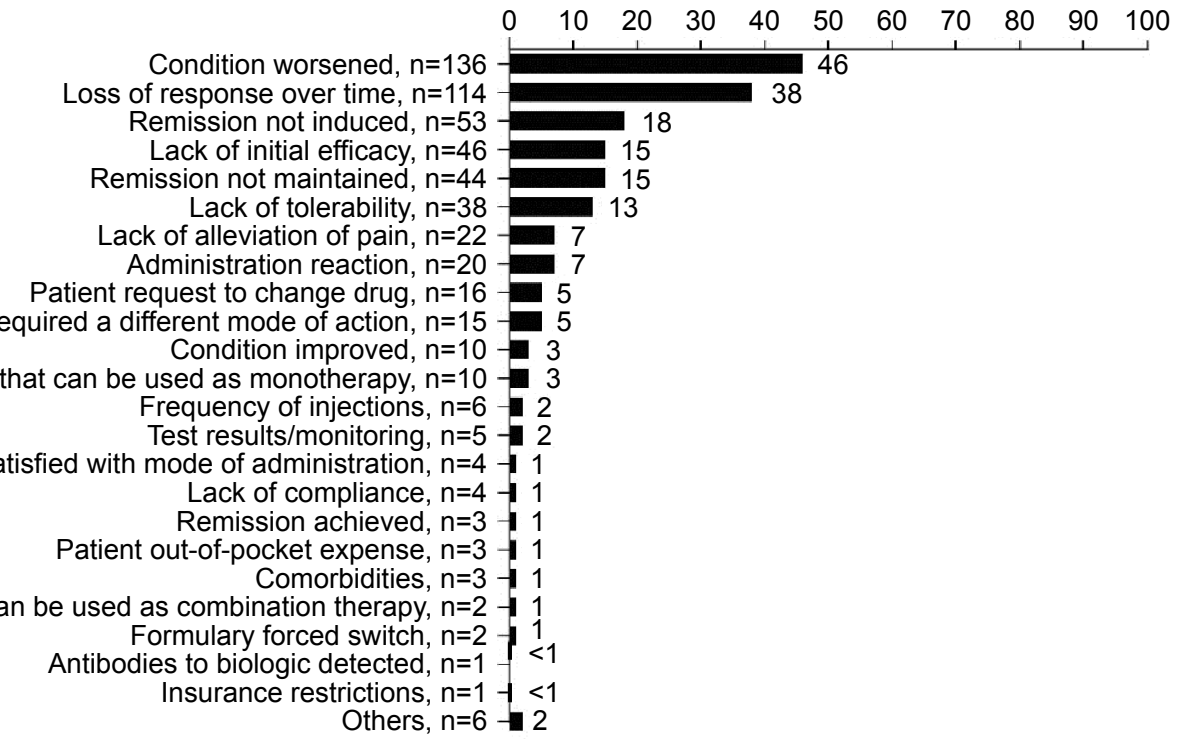

C

Physician-reported reason (\%)

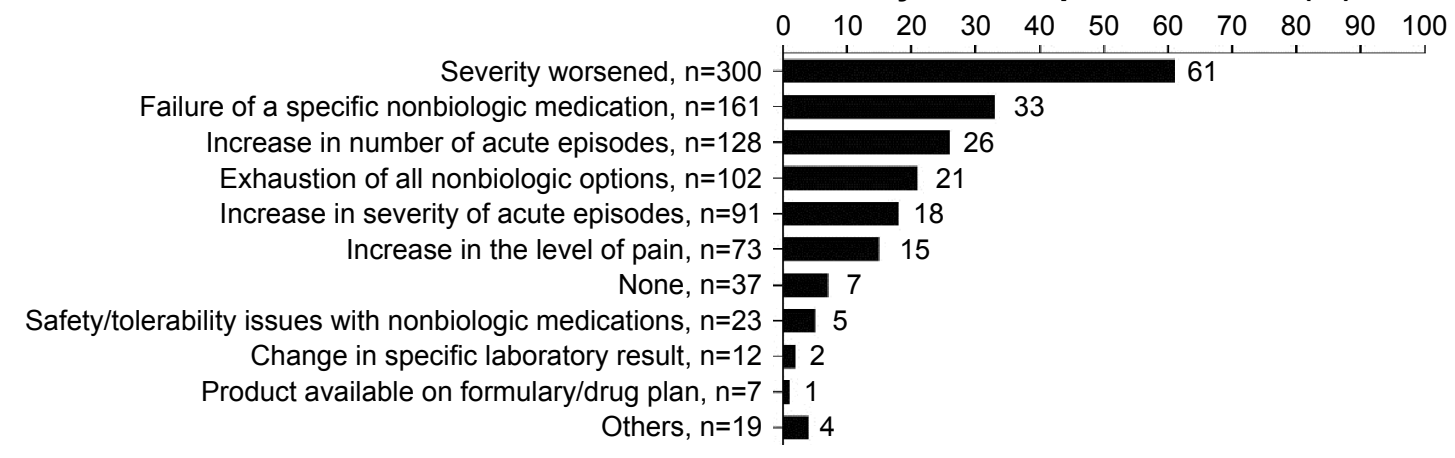

Figure I Factors influencing bDMARD treatment start.

Notes: Physicians could respond with more than one reason. (A) Physician-reported reasons for the choice of first-line bDMARD. Overall N=629. (B) Physician-reported reasons for switching previous bDMARD for current/most recent bDMARD. Overall N=297; physicians could only provide a reason for switching in the 297 patients who received two or more bDMARDs. (C) Physician-reported reasons that would prompt initiation of bDMARD therapy in bDMARD-naïve patients. Overall N=495. Abbreviations: bDMARD, biologic disease-modifying antirheumatic drug; DAS, disease activity score. 
Table 3 Baseline characteristics of patients across different T2T subgroups

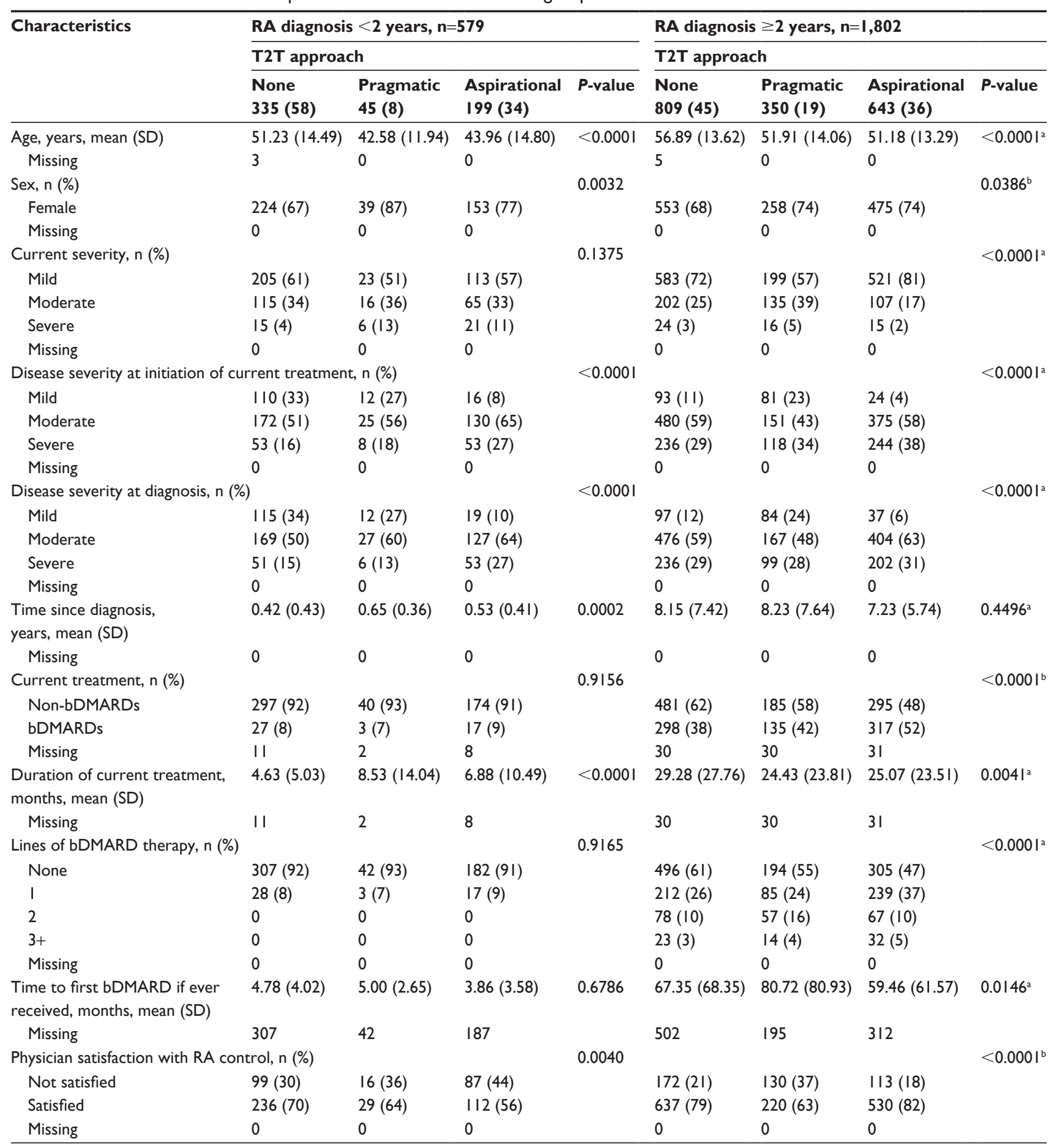

Notes: aKruskal-Wallis test. ${ }^{\mathrm{b}} \mathrm{Chi}$-squared test.

Abbreviations: bDMARD, biologic disease-modifying antirheumatic drug; RA, rheumatoid arthritis; T2T, treat-to-target.

previous studies showed that knowledge and implementation of T2T are both high among rheumatologists. ${ }^{21-23}$ Even when a T2T approach was implemented, it was mostly used in patients with $\geq 2$ years since RA diagnosis rather than in those with early disease (ie, RA diagnosis $<2$ years). However, a T2T approach is particularly recommended during the early phase of the disease when RA is not yet established and optimum disease control is more readily achieved, thereby preventing joint damage. The reasons for poor adoption of T2T recommendations in $2014^{24}$ can only be speculative because this specific question was not investigated. However, potential reasons include physician 
and/or patient dissatisfaction with therapeutic targets that concentrate solely on the attainment of disease activity states as recently published. ${ }^{25}$ Clinical time constraints precluding the ability to book frequent patient follow-ups that assess components of composite DASs can also contribute.

In terms of RA control, physicians' satisfaction was highest in patients who had been diagnosed with $R A \geq 2$ years compared with those with RA diagnosis $<2$ years. In the RA diagnosis $\geq 2$ years subset, the use of bDMARDs was also higher than in the RA diagnosis $<2$ years subgroup. This suggests that the lower satisfaction with outcome in early disease may be associated with delayed use of bDMARDs, although other factors could play a role as well.

In terms of limitations, this study was conducted in selected European countries and the results may not be an accurate reflection of other international practices. Furthermore, the sample may not be entirely representative of the practicing population of rheumatologists because the physicians participating in the DSP were those who met minimum workload criteria (regarding the number of RA patients they treat) for recruitment purposes. A certain degree of bias is expected because assessment of current disease activity relies on the physicians' accuracy in interpreting and reporting information. Therefore, patients of physicians who took part in this study may have characteristics that differ from those of physicians who declined to participate, thereby reducing the generalizability of the findings.

\section{Conclusion}

This cross-sectional analysis shows that the use of bDMARDs is suboptimal in patients with RA and that a T2T approach is not universally adopted.

\section{Acknowledgments}

We wish to thank all patients and rheumatologists who participated in the survey. Medical writing support was provided by Sabrina Giavara, PhD, of Engage Scientific Solutions and was funded by Pfizer.

\section{Author contributions}

ES and JP contributed to study concept, design, data collection, and interpretation. RW contributed to study concept and design, provided statistical support, and contributed to data interpretation. PCT, RA, JJGR, RC, and PB contributed to interpretation of data for the work. All authors contributed toward data analysis, drafting and critically revising the paper and agree to be accountable for all aspects of the work.

\section{Disclosure}

PCT has received fees from AbbVie, Bristol-Myers Squibb, Janssen, Lilly, Merck, Pfizer, Sandoz, Biogen, and UCB Pharma. RA has received fees from AbbVie, Bristol-Myers Squibb, Janssen, Lilly, Merck, Pfizer, Sandoz, Biogen, and UCB Pharma. JJGR has received fees from AbbVie, Biogen, Bristol-Myers Squibb, Hospira, Janssen, Merck, Pfizer, Regeneron, and UCB Pharma. RC has received fees from AbbVie, MSD, Pfizer, Roche, and UCB Pharma. PB has received fees from MSD, Pfizer, Reckitt Benckiser, and Roche. ES, RW, and JP are employees of Adelphi Real World and were contracted by Pfizer to provide data, input into design of data collection, and statistical support for the development of this study. This study was sponsored by Pfizer. Adelphi Real World was contracted by Pfizer to conduct the survey and provide data, input into design of data collection, and statistical support for the development of this study. Preliminary data from this study were presented as posters at the British Society for Rheumatology (BSR) Annual Meeting, April 26-28, 2016, Glasgow, Scotland, and at the Annual Scientific Meeting of the American College of Rheumatology/ Association of Rheumatology Health Professionals (ACR/ ARHP); November 6-11, 2015; San Francisco, CA, USA. The authors report no other conflicts of interest in this work.

\section{References}

1. Smolen JS, Aletaha D, Mcinnes IB. Rheumatoid arthritis. Lancet. 2016; 388(10055):2023-2038

2. Singh JA, Saag KG, Bridges SL, et al. 2015 American College of Rheumatology Guideline for the Treatment of Rheumatoid Arthritis. Arthritis Care Res. 2016;68(1):1-25.

3. Smolen JS, Landewé R, Bijlsma J, et al. EULAR recommendations for the management of rheumatoid arthritis with synthetic and biological disease-modifying antirheumatic drugs: 2016 update. Ann Rheum Dis. 2017;76(6):960-977.

4. Espinoza F, Fabre S, Pers YM. Remission-induction therapies for early rheumatoid arthritis: evidence to date and clinical implications. Ther Adv Musculoskelet Dis. 2016;8(4):107-118.

5. Monti S, Montecucco C, Bugatti S, Caporali R. Rheumatoid arthritis treatment: the earlier the better to prevent joint damage. RMD Open. 2015; 1(Suppl 1):e000057.

6. Smolen JS, Breedveld FC, Burmester GR, et al. Treating rheumatoid arthritis to target: 2014 update of the recommendations of an international task force. Ann Rheum Dis. 2016;75(1):3-15.

7. Smolen JS. Treat-to-target as an approach in inflammatory arthritis. Curr Opin Rheumatol. 2016;28(3):297-302.

8. Smolen JS. Treat-to-target: rationale and strategies. Clin Exp Rheumatol. 2012;30(4 Suppl 73):S2-S6.

9. Ridker PM. Moving toward new statin guidelines in a post-JUPITER world: principles to consider. Curr Atheroscler Rep. 2009;11(4): $249-256$.

10. Diabetes Control and Complications Trial Research Group. Effect of intensive diabetes treatment on the development and progression of long-term complications in adolescents with insulin-dependent diabetes mellitus: Diabetes Control and Complications Trial. Diabetes Control and Complications Trial Research Group. J Pediatr. 1994;125(2):177-188. 
11. Grigor C, Capell H, Stirling A, et al. Effect of a treatment strategy of tight control for rheumatoid arthritis (the TICORA study): a single-blind randomised controlled trial. Lancet. 2004;364(9430):263-269.

12. Knevel R, Schoels M, Huizinga TW, et al. Current evidence for a strategic approach to the management of rheumatoid arthritis with disease-modifying antirheumatic drugs: a systematic literature review informing the EULAR recommendations for the management of rheumatoid arthritis. Ann Rheum Dis. 2010;69(6):987-994.

13. Bakker MF, Jacobs JW, Welsing PM, et al. Low-dose prednisone inclusion in a methotrexate-based, tight control strategy for early rheumatoid arthritis: a randomized trial. Ann Intern Med. 2012;156(5):329-339.

14. Tugnet N, Pearce F, Tosounidou S, et al. To what extent is NICE guidance on the management of rheumatoid arthritis in adults being implemented in clinical practice? A regional survey. Clin Med. 2013;13(1): 42-46.

15. European Pharmaceutical Market Research Association (EphMRA) [webpage on the Internet]. Code of Conduct; 2017. Available from: http://www.ephmra.org/Code-of-Conduct-Support. Accessed June 28, 2017.

16. Gottlieb A, Korman NJ, Gordon KB, et al. Guidelines of care for the management of psoriasis and psoriatic arthritis: Section 2. Psoriatic arthritis: overview and guidelines of care for treatment with an emphasis on the biologics. J Am Acad Dermatol. 2008;58(5):851-864.

17. Greenapple R. Trends in biologic therapies for rheumatoid arthritis: results from a survey of payers and providers. Am Health Drug Benefits. 2012;5(2):83-92.

18. Lloyd S, Bujkiewicz S, Wailoo AJ, Sutton AJ, Scott D. The effectiveness of anti-TNF-alpha therapies when used sequentially in rheumatoid arthritis patients: a systematic review and meta-analysis. Rheumatology. 2010;49(12):2313-2321.
19. Rendas-Baum R, Wallenstein GV, Koncz T, et al. Evaluating the efficacy of sequential biologic therapies for rheumatoid arthritis patients with an inadequate response to tumor necrosis factor- $\alpha$ inhibitors. Arthritis Res Ther. 2011;13(1):R25.

20. Smolen JS, Burmester GR, Combe B, et al. Head-to-head comparison of certolizumab pegol versus adalimumab in rheumatoid arthritis: 2-year efficacy and safety results from the randomised EXXELERATE study. Lancet. 2016;388(10061):2763-2774

21. Caporali R, Conti F, Covelli M, et al. Treating rheumatoid arthritis to target: an Italian rheumatologists' survey on the acceptance of the treat-to-target recommendations. Clin Exp Rheumatol. 2014;32(4): 471-476.

22. Haraoui B, Bensen W, Bessette L, Le Clercq S, Thorne C, Wade J. Treating rheumatoid arthritis to target: a Canadian physician survey. J Rheumatol. 2012;39(5):949-953.

23. Hetland ML, Jensen DV, Krogh NS. Monitoring patients with rheumatoid arthritis in routine care: experiences from a treat-to-target strategy using the DANBIO registry. Clin Exp Rheumatol. 2014;32(5 Suppl 85): S141-S146.

24. Smolen JS, Landewé R, Breedveld FC, et al. EULAR recommendations for the management of rheumatoid arthritis with synthetic and biological disease-modifying antirheumatic drugs: 2013 update. Ann Rheum Dis. 2014;73(3):492-509.

25. Taylor PC, Alten R, Gomez-Reino JJ, et al. Clinical characteristics and patient-reported outcomes in patients with inadequately controlled rheumatoid arthritis despite ongoing treatment. RMD Open. 2018; 4(1):e000615
Patient Preference and Adherence

\section{Publish your work in this journal}

Patient Preference and Adherence is an international, peer-reviewed, open access journal that focuses on the growing importance of patient preference and adherence throughout the therapeutic continuum. Patient satisfaction, acceptability, quality of life, compliance, persistence and their role in developing new therapeutic modalities and compounds to optimize

\section{Dovepress}

clinical outcomes for existing disease states are major areas of interest for the journal. This journal has been accepted for indexing on PubMed Central. The manuscript management system is completely online and includes a very quick and fair peer-review system, which is all easy to use. Visit http://www. dovepress.com/testimonials.php to read real quotes from published authors. 